\title{
Homocystinuria due to methylene tetrahydrofolate reductase deficiency
}

INSERM

\section{Source}

INSERM. (1999). Orphanet: an online rare disease and orphan drug data base.

Homocystinuria due to methylene tetrahydrofolate reductase deficiency. ORPHA:395

Homocystinuria due to methylene tetrahydrofolate reductase (MTHFR) deficiency is a

metabolic disorder characterised by neurological manifestations. 